\title{
When saliva becomes a problem: the challenges and palliative care for patients with sialorrhea
}

\author{
Charles Christian Paine II ${ }^{1}$, James William Snider III $^{2}$ \\ ${ }^{1}$ Division of Pediatric Palliative and Complex Care, Department of Pediatrics, University of Mississippi School of Medicine, Jackson, MS, USA; \\ ${ }^{2}$ Department of Radiation Oncology, University of Alabama at Birmingham, UAB Proton Center, Birmingham, AL, USA \\ Contributions: (I) Conception and design: All authors; (II) Administrative support: All authors; (III) Provision of study materials or patients: All \\ authors; (IV) Collection and assembly of data: All authors; (V) Data analysis and interpretation: All authors; (VI) Manuscript writing: All authors; (VII) \\ Final approval of manuscript: All authors. \\ Correspondence to: James William Snider III, MD. Assistant Professor, Department of Radiation Oncology, University of Alabama at Birmingham, \\ UAB Proton Center, 400 20th Street S, Birmingham, AL 35233, USA. Email: jwsnider@uabmc.edu.
}

\begin{abstract}
Sialorrhea, or relative excess of salivary excretion, is a vexing problem for many patients. This symptom is precipitated by dysfunction in one of two interrelated processes-salivary production and oropharyngeal clearance. While medications primarily precipitate the former, dysphagia, often due to neurologic dysfunction, often causes the latter. This overabundance of saliva coupled with difficulty swallowing can predispose patients to respiratory issues, infections, and poor quality of life. There are, however, a myriad of treatment options that have shown clinical efficacy in treating this dysfunction. The purpose of this article is to present some background and etiology behind sialorrhea as well as present treatment options-non-pharmacologic, pharmacologic, surgical, and radiotherapeutic - that can help to ameliorate symptoms and improve quality of life for patients.
\end{abstract}

Keywords: Sialorrhea; palliative care

Submitted Sep 15, 2019. Accepted for publication Feb 06, 2020.

doi: 10.21037/apm.2020.02.34

View this article at: http://dx.doi.org/10.21037/apm.2020.02.34

\section{Introduction}

Normal salivary production is fundamental to good oral and gastrointestinal health. Saliva provides lubrication for the mouth, helps with swallowing, distributes food to taste buds, prevents bacterial overgrowth, and aids in preventing tooth decay and oral breakdown (1). Much has been written about the relative lack or deficiency in this important secretion-also called xerostomia. Namely, there have been multiple studies of xerostomia in patients taking certain medications, patients suffering from autoimmune diseases like Sjogren's, and in patients receiving radiotherapy (2). By contrast, sialorrhea, also known as hypersalivation or excessive salivary output, has garnered less attention.

Sialorrhea is precipitated by two primary mechanismsoverproduction/excessive secretion of saliva or, alternatively, poor oral clearance secondary to various forms of dysphagia.
In either case, the saliva then poses several additional risks to the patient. The first, and most obvious of these, is excess saliva spilling over the bottom lip leading to drooling, external skin irritations and breakdown, rashes, poor quality of life, and social ramifications (3). The second, and potentially more dangerous sequelae, are those affecting the respiratory system. With an inability to self-manage secretions, especially in patients with poor airway control and clearance, the one or more liters of saliva produced regularly each day can result in aspiration, choking, poor oxygenation, and life-threatening pneumonias (4). These patients require additional secretion management at baseline.

For physicians caring for patients with sialorrhea, it can be challenging to control secretions without precipitating the opposite state of xerostomia and its associated risks of oral and gastrointestinal issues. Perhaps more confounding is planning a treatment strategy for sialorrhea around 
the wide range of disease states that can lead to this symptom. Overproduction of saliva can result from certain medications, especially of the antipsychotic type, vitamin deficiencies, and gastroesophageal reflux (5). Alternatively, inability to clear secretions and dysphagia can lead to a secondary sialorrhea. This state often results from neurologic and neuromuscular disease-most commonly Parkinson's disease in adults (6) and Cerebral Palsy in children (7). Other causes include cancers of the head and neck and diseases such as amyotrophic lateral sclerosis (ALS).

Treatment teams must also consider the side-effects and varying effectiveness of available treatmentspharmacologic, non-pharmacologic, surgical, and radiotherapeutic. This review will provide a summary of the current epidemiology of the various forms of sialorrhea, examine the various disease states and other etiologies for the pathology, describe appropriate evaluation of the patient with hypersalivation, and, finally, provide treatment options for patients faced with these challenges.

\section{Etiology, scope, and epidemiology of sialorrhea}

As with many involuntary functions, proper salivary flow and control is regulated by a complex combination of body systems. The major glands responsible for production of saliva—sublingual, parotid, and submandibular-produce, on average, between 0.5 and $1.5 \mathrm{~L}$ of saliva in a day (8). This production responds to the autonomic nervous system and thus responds to both sympathetic (restricting salivary flow) and parasympathetic (increasing salivary flow) control (9). While sympathetic regulation occurs primarily through noradrenaline release, parasympathetic regulation is controlled by the medulla in the brain and acetylcholine outflow (10). Through the glossopharyngeal and facial nerves, there is a direct response to oral stimulation as well as conditioned responses like to smell. Increases in production will necessarily affect some part of this arc (8).

Many of the most challenging cases of sialorrhea, however, come not from overproduction but from inability to swallow and manage secretions. Swallowing involves multiple cranial nerves as well as voluntary and involuntary muscle movements throughout its four stages. These stages include oral preparatory, oral propulsive, pharyngeal, and esophageal phases (11). With liquids such as saliva, the process requires initial blockade of the mouth by the lips to prevent spillage as well as the tongue and soft palate preventing leakage of liquid into the oropharynx prematurely (8). Next the liquid bolus is propelled to the back of the mouth, where the pharyngeal phase is activated to propel it through the upper esophageal sphincter while protecting the airway from aspiration. The liquid bolus is then squeezed downward first by pharyngeal muscles and then by esophageal muscles as it proceeds to the stomach (12). This entire process is innervated by cranial nerves V, VII, IX, X, and XII (13).

This process can be complicated or completely disrupted in two primary ways: structurally and neurologically. Structural issues often arise as a result of trauma or mass (14). Neurological swallowing difficulty can arise from a multitude of neurodevelopmental and neurodegenerative issues. Among those commonly mentioned in the literature are Parkinson's, ALS, Cerebral Palsy, Alzheimer's, and stroke (15).

\section{Relevant etiologies for sialorrhea}

Sialorrhea is considered normal in newborns, but generally ceases by age 18 months and is pathologic after 4 years of age (16). Etiologies typically fall into one of several categories including anatomic disorders, sensory dysfunction, hypersecretion, and neuromuscular abnormalities (17).

Among the more common anatomic causes of sialorrhea are macroglossia, orthodontic abnormalities, dental malocclusion, incompetence of oral anatomy, and postoperative defects of the head and neck anatomy $(15,18)$.

Neuromuscular and sensory issues resulting in sialorrhea include Parkinson's disease, cerebral palsy, mental retardation, stroke, pseudobulbar abnormality, and bulbar palsy. These disorders can decrease the patient's ability to perform the normal compensatory mechanism for increased salivation-increased swallowing (17).

Hypersecretory conditions include inflammation due to dental caries, infections of the oral cavity, rabies, dental caries, adverse effects of anticonvulsants and tranquilizers, gastroesophageal reflux, and toxin exposure (15).

Finally, esophageal causes of sialorrhea can include inflammatory conditions such as Herpes Simplex Type I or Varicella Zoster virus, gastroesophageal reflux disease, cancer, strictures, achalasia, webs or rings, left atrial enlargement, Dysphagia Lusoria, and cervical osteophytes (5).

\section{Evaluation of sialorrhea}

Evaluation of sialorrhea involves both careful history-taking from the patient and caregivers, as well as various diagnostic steps. The best evaluation strategy is to involve a variety of 

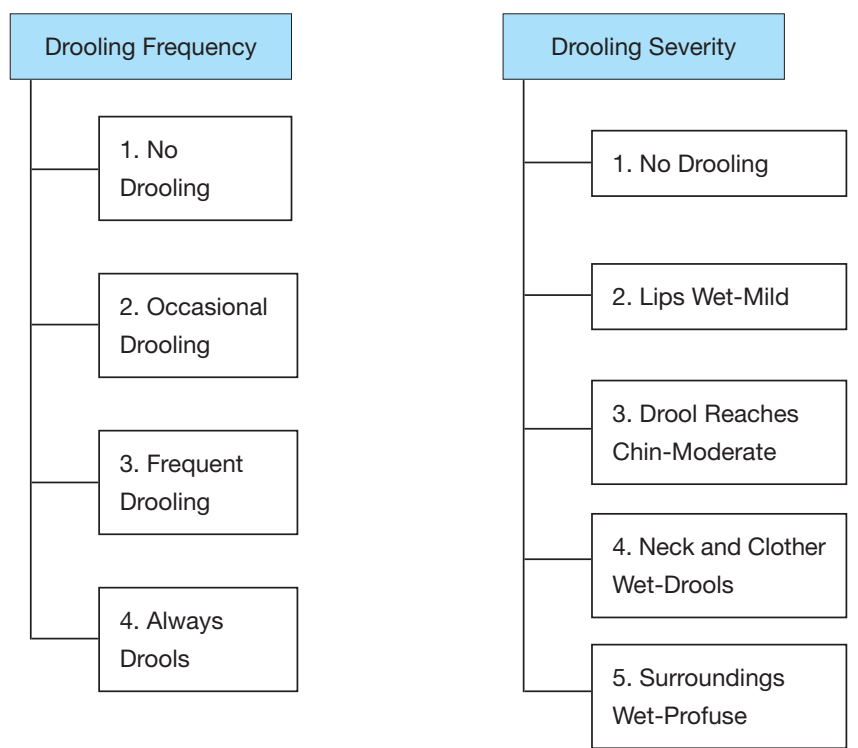

Figure 1 Diagram of the Drooling Severity and Frequency Scale, adapted from (22).

specialties in a multi-disciplinary approach (18).

Among the important aspects of the history are the assessment of orofacial motor skills, mood of the patient, positioning, and degree of activity (19). In addition, patients and caregivers should be questioned about the patient's language and communication abilities, medication list, presence of symptoms of gastroesophageal reflux disease, the presence of any respiratory disorders, and any recent or recurrent illnesses (15).

During the physical examination, multiple systems should also be evaluated. The presence of jaw abnormalities, blockage of the nasal passages, dental abnormalities, abrasions or ulcers on the lips, abnormalities of the chin or oral cavity, presence of macroglossia, poor tongue movement, and enlargement of the tonsils should all be assessed (15). Other important aspects of evaluation include testing of the cranial nerves and oropharyngeal muscular function (19). The level of alertness, overall motor skills, sensory abnormalities, and dysphagia are also significant $(15,19)$.

In terms of severity quantification, various scales have been evaluated. While measurement of the amount of salivation can be done by chip cup collections or soaked bib weights, these assessment methods are not well validated or methodologically standardized $(19,20)$. On the other hand, monitoring over time can be done using scales such as the Teacher Drooling Scale (21). The Drooling Severity and Frequency Scale has also been widely used in the assessment of the severity of sialorrhea (22) (Figure 1).
Various diagnostic modalities can also be utilized based on the suspected etiology for the sialorrhea. Patients with possible cranial nerve causes of sialorrhea should have an MRI of the head to clarify the pathology that may have resulted in this etiology (19).

If the patient has suspected involvement of the upper esophagus in the pathology of his/her sialorrhea, the patient should have a modified barium swallow with videofluoroscopy performed by a speech language pathologist and radiologist (23). During this evaluation, assessment for aspiration can also be performed. Another newer modality for evaluation of this type of pathology is the use of real-time MRI; however, this modality is not widely available (19).

If the patient does have suspected aspiration, the patient should be evaluated by a speech language pathologist with a bedside swallowing evaluation. During this evaluation and the modified barium swallow, the speech pathologist can identify issue such as the food or liquid bolus going into the pharynx and pharyngeal phase swallowing disorders. Fiberoptic endoscopic evaluation of swallowing (FEES) should also be done in this situation (24).

\section{Non-pharmacologic management options for sialorrhea}

Whenever possible, non-pharmacologic management is, of course, preferred to other modalities. Non-pharmacologic management of sialorrhea can include orthodontic 
procedures, functional dysphagia therapy, respiratory therapy maneuvers, and neurosensory therapies.

If the patient has maloccluded or malpositioned teeth or jaws, orthodontic procedures are the management of choice. Among orthodontic options include palatal stimulation plates; these plates have an attached wire in the posterior portion that stimulates the soft palate and can particularly help patients with jaw malposition (25). These plates should only be used in children over 6 years old and they require creation from a dental impression for individualized fitting of the plate (26). Mouth vestibular braces can also be added to the plates in order to result in lip closure. Other modalities attached to these plates can help with improving tongue base positioning and closure of the mouth, which can result in less hypersalivation (19).

Functional dysphagia therapy is particularly helpful in patients with oropharyngeal dysphagia resulting in inability to swallow saliva (27). This therapy has been shown to reduce aspiration (28) and is thought to result in reorganization of the motor cortex in patients with brain pathology (19). Functional therapy also decreases the need for surgeries, particularly in young children (29).

Functional dysphagia therapy has three main partsrestitution, compensation, and adaptation. Restitution is used to restore disordered function and is also called indirect swallowing therapy. In this part of the therapy, the stimulus is initiated and then abnormal reflex activities are decreased, the swallowing reflex is stimulated, and the movements of each portion of the swallow are strengthened. The compensation portion of this therapy consists of learning alternative ways to control swallowing despite abnormalities remaining present. Among these compensatory strategies are the Mendelsohn maneuver, effortful swallowing, and supraglottic swallowing. Adaptation involves changing the type of diet or food consistency to accommodate the abnormality (27).

Patients with sialorrhea can also have reduced cough, either in frequency or effectiveness, which can increase risks of pneumonia and aspiration. In order to ameliorate this issue, a mechanical insufflator-exsufflator can be used (often called a cough-assist device) (30).

Finally, in order to manage insufficient tone of the orofacial muscles, neurosensory therapies can be used. This condition is the most common etiology of sialorrhea in children and neurosensory stimulation can result in improved oropharyngeal reflex development (31). Additionally, kinesio-taping has been used to assist in improving oropharyngeal muscle tone in children with neurologic disorders (32).

\section{Pharmacologic management for sialorrhea}

Various pharmacologic agents have been used in the management of sialorrhea. Of note, none of these agents are specifically FDA-approved for sialorrhea and are, instead, often used off-label. Therefore, there may be implications in terms of insurance and payment for these drugs (19). Among the pharmacologic agents most commonly used are glycopyrrolate, scopolamine, atropine, and benztropine. Botulinum toxin injection into the salivary glands has also been used.

Glycopyrrolate is an anticholinergic agent that results in reversible $\mathrm{M} 3$ muscarinic receptor antagonism and thus secretion of saliva is reduced. This agent only minimally crosses the blood-brain barrier due to its quaternary structure, as opposed to other agents used (33). The drug should be dosed by body weight and kidney function as per the package insert. In one study, glycopyrrolate reduced drooling in $90 \%$ of patients, but $28 \%$ of patients dropped out of the study due to side effects (34). The reduction of drooling in patients taking this drug was also demonstrated in another study; however, adverse effects occurred in up to $20 \%$ of patients and included diarrhea, vomiting, flushing, pyrexia, dry mouth, and nasal congestion (33).

Scopolamine is another anticholinergic medication used for sialorrhea. One advantage of this medication is that is can be given transdermally, sublingually, subcutaneously, via PEG tube, or intravenously (19). The transdermal patch has been shown to result in continuous, slow release over 3 days (35).

Atropine has been studied in Parkinson's patients and was effective in reducing sialorrhea in the sublingual form in one study (36). Atropine has also been used in treating sialorrhea secondary to clozapine (36,37). Benztropine is another anticholinergic agent used in the treatment of sialorrhea. In one small study, $85 \%$ of patients treated with benztropine responded versus only $15 \%$ with placebo (21).

The adverse effects and contraindications of these anticholinergic drugs can, unfortunately, limit their use. Among the contraindications are a history of urinary retention, myasthenia gravis, and narrow-angle glaucoma. The adverse effects include confusion, excitability, urinary retention, constipation, and visual abnormalities, among others (19).

Botulinum toxin can be injected into the large salivary glands as another option to treat sialorrhea; most of the studies have been done with toxin A, but toxin B has also been evaluated. This injection results in cholinergic transmission inhibition and thus reduced salivary output (38). Botulinum toxin A is typically administered by 
injection of 30 units into the parotid glands and 20 units into the submandibular glands. Injection into the parotid glands and the submandibular glands is performed (19), and ultrasound-guided injection of the submandibular gland in particular is used in order to reduce diffusion of the medication into the oral floor musculature $(19,39)$. While the medication's effects are not lifelong, it is typically efficacious for 3-4 months (40), during which time other non-invasive treatment modalities can be used. Botulinum toxin can also be injected into the upper esophageal sphincter to treat etiologies of sialorrhea in this area (41).

Anti-reflux agents and beta blockers have also been investigated (42). Anti-reflux agents did not result in improvement in drooling in one study (43), and beta blockers did result in decreased thick secretions in another study, but the study was very small and poorly designed (44).

\section{Surgical management for sialorrhea}

Surgical options for sialorrhea can be considered in wellselected patients. Oral functional disorders in young children need to be evaluated first, as if they are present, functional dysphagia therapies would be indicated over surgery (19). Surgical options to ameliorate sialorrhea secondary to restricted nasal breathing include rhino-surgical procedures, tonsillectomies, and adenoidectomies, but these procedures should only be considered in severe cases due to the risks of general anesthesia in these patients (19).

Other surgical options include excision of the salivary glands and displacement or ligation of the ducts. Excision of the submandibular gland is thought to remove resting salivary flow, but given the significant complications including facial paresis, paralysis, nerve injury, and wound infections, most surgeons only offer this procedure in very limited cases (45). Bilateral rerouting of the submandibular ducts is another procedure performed by otolaryngologists to treat sialorrhea; in one metanalysis including 21 studies of this procedure, the subjective success rate was $84.4 \%$ (46). Additional surgical procedures for sialorrhea include parotid duct rerouting, ligation of the parotid duct, and transtympanic neuroectomy. A combination of multiple surgical techniques, submandibulectomy with bilateral parotid duct ligation, is very successful with few adverse effects and good satisfaction (17).

Additional surgical options in specific pathologies include cricopharyngeal myotomy or bougie dilation in patients with upper esophageal sphincter disorders (47). Osteotomy of the jaw can also be used for patients with frontally open bit disorders (19).

\section{Radiotherapeutic management of sialorrhea}

External beam radiation can be used as another modality in severe cases of sialorrhea. This modality for therapy of sialorrhea was developed based on the known side effect of xerostomia that develops in patients who have received radiation for head and neck cancer (19). The mechanism of xerostomia induction by megavoltage $\mathrm{X}$-ray therapy is multifactorial, but acute, subacute, and persistent xerostomia is ubiquitously encountered when the major salivary glands, parotid/submandibular, are exposed to lowmoderate doses of radiation.

One study showed that $82 \%$ of 34 patients receiving radiation for sialorrhea achieved a satisfactory response with only 4 patients experiencing long-term adverse effects. In this study, electron therapy resulted in greater response rates $v s$. orthovoltage therapy and treatment of both the parotid and the submandibular glands resulted in superior effects (48). Another systematic review of 10 studies showed that external beam radiation therapy given at median dose 12 Gy resulted in subjective improvement over baseline in $81 \%$ of patients studied (49). Another prospective study of 50 ALS patients showed improvement of all patients after radiotherapy (50). This study concluded that therapy of 20 Gy in 4 fractions effectively treated symptoms of sialorrhea without any level 3 or 4 toxicity. The authors also posited that a course of 10 Gy in 2 fractions could potentially be used in medically high-risk patients (50).

Irradiation can also be used for patients who had persistent hypersalivation despite botulinum toxin injection or who have salivary fistulas after surgery $(49,51)$.

\section{Conclusions}

Sialorrhea can be a very difficult problem to face both as a patient and as a clinician. Its ramifications for quality of life as well as respiratory health are serious facets of any disease and must be treated as such. Many times, one intervention alone is not enough and, as with any therapy, treatment must be targeted to the specific and changing needs of each individual patient. Whether patients are suffering from a medication side-effect, a neurologic dysfunction or syndrome, or the difficulties of living with cancer, it is vital that clinicians be familiar with the entire 'tool-box' of options to treat sialorrhea in order to improve the lives of patients. 


\section{Acknowledgments}

Funding: None.

\section{Footnote}

Provenance and Peer Review: This article was commissioned by the Guest Editors (Jan Gaertner, Charles B. Simone II and Fiona Lim) for the series "Clinical Challenges and Pitfalls in Early Palliative Care: Practical Knowledge and Guidance from other Medical Specialties" published in Annals of Palliative Medicine. The article was sent for external peer review organized by the Guest Editors and the editorial office.

Conflicts of Interest: Both authors have completed the ICMJE uniform disclosure form (available at http://dx.doi. org/10.21037/apm.2020.02.34). The series "Clinical Challenges and Pitfalls in Early Palliative Care: Practical Knowledge and Guidance from other Medical Specialties" was commissioned by the editorial office without any funding or sponsorship. Dr. Snider declares the following conflicts of interest: Varian Medical Systems Honorarium, UM Ventures grant for novel mucositis mitigation device development, MIPS grant for GammaPod device development, Patent pending for novel proton therapy technique, Siemens Healthineers consultant funding, travel grants from Pyrexar/STM, Hefei Ion Center Symposium, Moscow ONE Symposium, CSCO Varian, PTCOG Varian. None of these have substantially biased the work or opinions, herein. The authors have no other conflicts of interest to declare.

Ethical Statement: The authors are accountable for all aspects of the work in ensuring that questions related to the accuracy or integrity of any part of the work are appropriately investigated and resolved.

Open Access Statement: This is an Open Access article distributed in accordance with the Creative Commons Attribution-NonCommercial-NoDerivs 4.0 International License (CC BY-NC-ND 4.0), which permits the noncommercial replication and distribution of the article with the strict proviso that no changes or edits are made and the original work is properly cited (including links to both the formal publication through the relevant DOI and the license). See: https://creativecommons.org/licenses/by-nc$\mathrm{nd} / 4.0 /$.

\section{References}

1. Dawes C, Pedersen AM, Villa A, et al. The functions of human saliva: A review sponsored by the World Workshop on Oral Medicine VI. Arch Oral Biol 2015;60:863-74.

2. Guggenheimer J, Moore PA. Xerostomia: etiology, recognition and treatment. J Am Dent Assoc 2003;134:61-9; quiz 118-9.

3. Chou KL, Evatt M, Hinson V, et al. Sialorrhea in Parkinson's disease: a review. Mov Disord 2007;22:2306-13.

4. Rodrigues B, Nobrega AC, Sampaio M, et al. Silent saliva aspiration in Parkinson's disease. Mov Disord 2011;26:138-41.

5. Boyce $H W$, Bakheet MR. Sialorrhea: a review of a vexing, often unrecognized sign of oropharyngeal and esophageal disease. J Clin Gastroenterol 2005;39:89-97.

6. Tan EK. Botulinum toxin treatment of sialorrhea: comparing different therapeutic preparations. Eur J Neurol 2006;13 Suppl 1:60-4.

7. Suskind DL, Tilton A. Clinical study of botulinum-A toxin in the treatment of sialorrhea in children with cerebral palsy. Laryngoscope 2002;112:73-81.

8. Pedersen AM, Bardow A, Jensen SB, et al. Saliva and gastrointestinal functions of taste, mastication, swallowing and digestion. Oral Dis 2002;8:117-29.

9. Proctor GB, Carpenter GH. Salivary secretion: mechanism and neural regulation. Monogr Oral Sci 2014;24:14-29.

10. Proctor GB, Carpenter GH. Regulation of salivary gland function by autonomic nerves. Auton Neurosci 2007;133:3-18.

11. Jones K, Pitceathly RD, Rose MR, et al. Interventions for dysphagia in long-term, progressive muscle disease. Cochrane Database Syst Rev 2016;2:CD004303.

12. Matsuo K, Palmer JB. Anatomy and physiology of feeding and swallowing: normal and abnormal. Phys Med Rehabil Clin N Am 2008;19:691-707, vii.

13. Martin RE, Sessle BJ. The role of the cerebral cortex in swallowing. Dysphagia 1993;8:195-202.

14. McCulloch TM, Jaffe D. Head and neck disorders affecting swallowing. GI Motil Onl 2006. doi:10.1038/gimo36.

15. Güvenç IA. Sialorrhea: A Guide to Etiology, Assessment, and Management. Salivary Glands-New Approaches in Diagnostics and Treatment. IntechOpen 2018. doi: 10.5772/intechopen.82619.

16. Fairhurst CB, Cockerill H. Management of drooling in children. Arch Dis Child Educ Pract Ed 2011;96:25-30.

17. Hockstein NG, Samadi DS, Gendron K, et al. Sialorrhea: a management challenge. Am Fam Physician 2004;69:2628-34.

18. Crysdale WS, McCann C, Roske L, et al. Saliva control issues in the neurologically challenged. A 30 year experience in team management. Int $\mathrm{J}$ Pediatr Otorhinolaryngol 2006;70:519-27.

19. Steffen A, Jost W, Baumer T, et al. Hypersalivation: update of the German S2k guideline (AWMF) in short form. J 
Neural Transm (Vienna) 2019;126:853-62.

20. Blasco PA, Allaire JH. Drooling in the developmental disabled: management practices and recommendations. Dev Med Child Neurol 1992;34:849-62.

21. Camp-Bruno JA, Winsberg BG, Green-Parsons AR, et al. Efficacy of benztropine therapy for drooling. Dev Med Child Neurol 1989;31:309-19.

22. Thomas-Stonell N, Greenberg J. Three treatment approaches and clinical factors in the reduction of drooling. Dysphagia 1988;3:73-8.

23. Holzapfel K. Radiologische Diagnostik von Schluckstörungen. In: Bartolome G, Schröter-Morasch H, Buchholz D. editors. Schluckstörungen-Diagnostik und Rehabilitation. Amsterdam: Elsevier, 2014.

24. Tutor JD, Gosa MM. Dysphagia and aspiration in children. Pediatr Pulmonol 2012;47:321-37.

25. Asher RS, Winquist $H$. Appliance therapy for chronic drooling in a patient with mental retardation. Spec Care Dentist 1994;14:30-2.

26. Little SA, Kubba H, Hussain SS. An evidence-based approach to the child who drools saliva. Clin Otolaryngol 2009;34:236-9.

27. Prosiegel M, Schelling A, Wagner-Sonntag E. Dysphagia and multiple sclerosis. Int MS J 2004;11:22-31.

28. Hinchey JA, Shephard T, Furie K, et al. Formal dysphagia screening protocols prevent pneumonia. Stroke 2005;36:1972-6.

29. Limbrock J. Mundmotorik: Empfehlungen für Babys und Kleinkinder mit Störungen der oralen Funktion. Osteopathische Medizin 2017;18:38-41.

30. Steffen A, Jost W, Bäumer T, et al. Hypersalivation: Update of the German S2k Guideline in Short Form. J Neural Transm 2019;126:853-62.

31. Silvestre-Rangil J, Silvestre FJ, Puente-Sandoval A, et al. Clinical-therapeutic management of drooling: Review and update. Med Oral Patol Oral Cir Bucal 2011;16:e763-6.

32. Mikami DLY, Furia CLB, Welker AF. Addition of Kinesio Taping of the orbicularis oris muscles to speech therapy rapidly improves drooling in children with neurological disorders. Dev Neurorehabil 2019;22:13-8.

33. Zeller RS, Davidson J, Lee HM, et al. Safety and efficacy of glycopyrrolate oral solution for management of pathologic drooling in pediatric patients with cerebral palsy and other neurologic conditions. Ther Clin Risk Manag 2012;8:25-32.

34. Blasco PA, Stansbury JC. Glycopyrrolate treatment of chronic drooling. Arch Pediatr Adolesc Med 1996;150:932-5.

35. Brodtkorb E, Wyzocka-Bakowska MM, Lillevold PE, et al. Transdermal scopolamine in drooling. J Ment Defic Res 1988;32:233-7.

36. Hyson HC, Johnson AM, Jog MS. Sublingual atropine for sialorrhea secondary to parkinsonism: a pilot study. Mov Disord 2002;17:1318-20.
37. Mustafa FA, Khan A, Burke J, et al. Sublingual atropine for the treatment of severe and hyoscine-resistant clozapine-induced sialorrhea. Afr J Psychiatry (Johannesbg) 2013;16:242 .

38. Ellies M, Rohrbach-Volland S, Arglebe C, et al. Successful management of drooling with botulinum toxin A in neurologically disabled children. Neuropediatrics 2002;33:327-30.

39. Jost WH. The option of sonographic guidance in Botulinum toxin injection for drooling in Parkinson's disease. J Neural Transm (Vienna) 2016;123:51-5.

40. Fuster Torres MA, Berini Aytes L, Gay Escoda C. Salivary gland application of botulinum toxin for the treatment of sialorrhea. Med Oral Patol Oral Cir Bucal 2007;12:E511-7.

41. Alberty J, Oelerich M, Ludwig K, et al. Efficacy of botulinum toxin A for treatment of upper esophageal sphincter dysfunction. Laryngoscope 2000;110:1151-6.

42. Tscheng DZ. Sialorrhea - therapeutic drug options. Ann Pharmacother 2002;36:1785-90.

43. Heine RG, Catto-Smith AG, Reddihough DS. Effect of antireflux medication on salivary drooling in children with cerebral palsy. Dev Med Child Neurol 1996;38:1030-6.

44. Newall AR, Orser R, Hunt M. The control of oral secretions in bulbar ALS/MND. J Neurol Sci 1996;139 Suppl:43-4.

45. Martin TJ, Conley SF. Long-term efficacy of intra-oral surgery for sialorrhea. Otolaryngol Head Neck Surg 2007;137:54-8.

46. Reed J, Mans CK, Brietzke SE. Surgical management of drooling: a meta-analysis. Arch Otolaryngol Head Neck Surg 2009;135:924-31.

47. Lawson G, Remacle M. Endoscopic cricopharyngeal myotomy: indications and technique. Curr Opin Otolaryngol Head Neck Surg 2006;14:437-41.

48. Borg M, Hirst F. The role of radiation therapy in the management of sialorrhea. Int J Radiat Oncol Biol Phys 1998;41:1113-9.

49. Hawkey NM, Zaorsky NG, Galloway TJ. The role of radiation therapy in the management of sialorrhea: $\mathrm{A}$ systematic review. Laryngoscope 2016;126:80-5.

50. Assouline A, Levy A, Abdelnour-Mallet M, et al. Radiation therapy for hypersalivation: a prospective study in 50 amyotrophic lateral sclerosis patients. Int J Radiat Oncol Biol Phys 2014;88:589-95.

51. Laskawi R, Winterhoff J, Kohler S, et al. Botulinum toxin treatment of salivary fistulas following parotidectomy: follow-up results. Oral Maxillofac Surg 2013;17:281-5.

Cite this article as: Paine CC 2nd, Snider JW 3rd. When saliva becomes a problem: the challenges and palliative care for patients with sialorrhea. Ann Palliat Med 2020;9(3):1333-1339. doi: 10.21037/apm.2020.02.34 